\title{
INNOVACIÓN Y TRADICIÓN EN EL LÉXICO DE LAS TRADUCCIONES BÍBLICAS CASTELLANAS MEDIEVALES: EL USO DE CULTISMOS Y VOCES PATRIMONIALES EN LAS VERSIONES DEL SIGLO XV ${ }^{1}$
}

\author{
INNOVATION AND TRADITION IN THE LEXICON OF \\ MEDIEVAL SPANISH BIBLICAL TRANSLATIONS: LEARNED AND \\ VERNACULAR WORDS IN FIFTEENTH-CENTURY BIBLES
}

\author{
F. JAVIER Pueyo MENA, ANDRÉS ENRIQUe-ARIAS \\ Universitat de les Illes Balears
}

\begin{abstract}
Resumen: En este trabajo se aborda el uso de cultismos y otras innovaciones léxicas y morfológicas en los cuatro romanceamientos medievales completos de la Biblia hebrea compuestos en el siglo $X V$. Para ello se analiza una selección de lemas hebreos y de sus traducciones castellanas correspondientes, así como la distribución de ciertos fenómenos de morfología derivativa. El objetivo es determinar, mediante la comparación cuantitativa y cualitativa de las soluciones romances empleadas, el reparto de léxico vernáculo tradicional frente a innovaciones cultas. Nuestros resultados muestran que mientras la Biblia de Arragel y la Biblia del Marqués de Santillana se muestran inmersas en la tendencia de principios del siglo XV hacia el uso de cultismos y estructuras latinizantes, los textos más tradicionales, como la Biblia E3, no los presentan de forma apreciable. La Biblia $E 5 / E 7$, por otro lado, queda a medio camino respecto del resto de las versiones, haciendo uso por lo general de opciones
\end{abstract}

\begin{abstract}
This paper analyses the variation in the use of learned vocabulary as well as other lexical and morphological innovations in four Spanish medieval translations of the Hebrew Bible composed during the fifteenth century. In order to do so, we analyze a selection of Hebrew lemmas and their corresponding Spanish translations, as well as the distribution of a number of derivational morphology phenomena. Our goal is to determine, through a quantitative and qualitative comparison of the Romance variants used by the translators, the distribution of traditional vernacular lexicon and learned innovations. Our results show that while the Arragel Bible and the Bible of the Marques de Santillana are immersed in the early fifteenth century trend of incorporating learned and latinate structures, other traditional texts, such as the $B i$ ble E3, do not use such words. The Bible $E 5 / E 7$, on the other hand, lays somewhere between those two types as it exhibits some of the traditional lexical options, as
\end{abstract}

\footnotetext{
${ }^{1}$ En este trabajo hemos normalizado los ejemplos citados y usamos las siguientes abreviaturas: E3 = Escorial I.i.3; E4 = Escorial I.i.4; Ajuda = Biblioteca de Ajuda, Lisboa, 52-xii-1; E7/E5 = Escorial I.i.7 / Escorial I.i.5; Évora = Biblioteca Pública, Évora, ms. cxxiv/1-2; E19 $=$ Escorial I.ii.19; BNE = Biblioteca Nacional de España ms. 10288; RAH = Real Academia de la Historia ms. 87; Santillana $=$ Pentateuco de E4 + BNE 10288; Arragel = Palacio de Liria, Madrid; Oxford = Bodleian Library, Canon. Ital. 177, Oxford .
} 
tradicionales en la línea de E3, pero incorporando igualmente voces cultas aunque en menor medida que las Biblias de Santillana y de Arragel.

Palabras clave: Biblia; traducción; Edad Media; castellano medieval; cultismo; voces patrimoniales. the E3 translation, but also incorporates a small number of learned words, although to a lesser extent than the Arragel and Santillana Bibles.

Keywords: Bible; translation; Middle Ages; old Spanish; learned words; patrimonial words.

\section{SUMARIO}

1. Introducción.- 2. Distribución general: léxico tradicional frente a léxico de autor.3. Análisis de la traducción de algunos lemas hebreos.- 4. Morfología derivativa.4.1. Dos sufijos decididamente innovadores: -ísimo y -mente.-4.2. Sufijos derivativos en competencia: tradición (-ura,-miento) frente a innovación (-ción,-idad).- 5. El participio de presente: tradición e innovación en una estructura léxico-sintáctica.- 6. Caracterización de los romanceamientos.- 6.1. El estilo tradicional de E3.- 6.2. El estilo variable de E7/E5.- 6.3. El "sabio" converso Lucena.- 6.4. El "sabio" rabino Arragel.- 7. Conclusión.- 8. Bibliografía citada.- Apéndice.

\section{INTRODUCCIÓN}

La traducción de la Biblia al castellano presenta en el siglo XV una doble singularidad, tanto en el orden cuantitativo como en el cualitativo. En cuanto al número de traducciones, el primer tercio del siglo XV es el periodo en que se produce la gran mayoría de los romanceamientos castellanos con un volumen de producción de traducciones bíblicas que no tiene paralelo en la Europa de la época ${ }^{2}$. El propio contenido de las traducciones es igualmente singular en el contexto europeo pues se hacen a partir de la lengua original, el hebreo, y no sobre el texto canónico de la Iglesia, es decir, la Vulgata latina de san Jerónimo, como es habitual en la Europa medieval ${ }^{3}$. Aún más sorprendente que la lengua de origen lo es el origen de los traductores, todos ellos judíos, lo cual como veremos a lo largo de estas páginas no solo nos sitúa en una

\footnotetext{
${ }^{2}$ Mientras que las traducciones a los vernáculos medievales son, para cada lengua, manifiestamente pocas (los casos en que, como en francés o italiano, tenemos un enorme número de testimonios, se trata de copias o revisiones de una misma versión), en Castilla contamos para el siglo XV hasta con seis versiones diferentes de amplios segmentos bíblicos ( $c f$. Pueyo Mena y Enrique-Arias 2013), un número considerable si tenemos en cuenta además que seguramente existieron más ejemplares que no han sobrevivido a los avatares del tiempo.

${ }^{3}$ Una tradición antigua en castellano, como muestran los fragmentos bíblicos traducidos del hebreo en la Fazienda de ultramar, de principios del siglo XIII, y de la que podemos percibir cierta continuidad en las glosas romances (le'azim) producidas en la segunda mitad del XIII ( $c f$. Barco 2011) y las abundantes citas bíblicas en la literatura polémica del siglo XIV (Szpiech, en prensa).
} 
tradición particular de traducción, alejándonos del tipo de traducción erudita realizada por hebraístas y latinistas cristianos en siglos posteriores o en otros países, sino que nos permite observar la tensión lingüística entre la expresión de dicha tradición judía en la traducción del texto sagrado y los intentos de los traductores por adaptarse tanto al público cristiano al que se dirigen como al ambiente cultural pre-humanista y de renovación lingüística característico del siglo XV.

Esta tensión se refleja en todos los ámbitos de la lengua de traducción, tanto al comparar las Biblias entre sí como dentro de una misma traducción: junto al mantenimiento de algunas estructuras sintácticas del hebreo encontramos numerosos intentos de adaptación a la sintaxis castellana, frente a la aceptación de ciertos aspectos morfológicos del hebreo se produce paralelamente el rechazo de los mismos mediante el uso de las formas romances habituales, a la mera transcripción o transliteración de topónimos o antropónimos bíblicos en su forma original hebrea se opone el uso de las formas conocidas en la tradición cristiana, junto al uso de la exégesis judía para la traducción de ciertos pasajes encontramos numerosos casos de traducción literal no interpretativa que separa puntualmente dicho pasaje de la tradición judía ${ }^{4}$. Y, desde luego, tal y como examinamos a lo largo de este trabajo, es destacable la tensión entre el uso del léxico bíblico tradicional judío (sea este exclusivo del uso judío o compartido con los hablantes cristianos durante la Edad Media) y la incorporación de vocablos más modernos, bien en la forma de cultismos generales más o menos adaptados, de latinismos crudos provenientes de la Vulgata latina o mediante mecanismos de creación léxica que incorporan componentes morfológicos novedosos.

Dichos fenómenos lingüísticos reflejan la doble culturalidad de los encargados de llevar a cabo la tarea de traducción, inmersos, por un lado, en la cultura tradicional intracomunitaria de las aljamas judías (en las que viven y profesan su religión o, en el caso de traductores conversos, en las que se han educado durante gran parte de su vida), y, por otro, en la cultura castellana que se está abriendo a nuevas corrientes culturales, a través precisamente de la labor de los traductores de obras clásicas o europeas.

Pocos son los datos históricos que nos permiten identificar de forma concreta los actores que participan en los proyectos de traducción que han llegado hasta nosotros. En la mayor parte de los casos, como en los manuscritos

\footnotetext{
${ }^{4}$ Véase, por ejemplo, Enrique-Arias 2004, 2006, donde se analizan ejemplos concretos de la combinación de elementos del texto subyacente hebreo con la influencia latinizante propia del XV en la traducción de la Biblia de Arragel.
} 
E3 o E195, sabemos que los traductores son judíos, no solo porque traducen del hebreo, y no solo porque sus traducciones incorporan el uso de exégesis judía o de formas lingüísticas particulares de los judíos, sino porque mantienen dentro de la traducción elementos de división y disposición del texto hebreo que son inequívocamente judíos. Sabemos también que los destinatarios de dichas traducciones no eran judíos, sino nobles castellanos cristianos, no solo por las adaptaciones evidentes de topónimos o antropónimos para lectores cristianos, o por el uso en la escritura del alfabeto latino y no de la tradicional aljamía hebraica, sino también porque los códices presentan escudos nobiliarios (E3, E4), colofones (Évora), y otros rasgos materiales que así nos lo indican (desde el programa iconográfico, a la colocación de libros siguiendo el orden de la Vulgata o la inclusión de libros deuterocanónicos traducidos del latín que no tienen sentido en el mundo religioso judío, o la presentación en paralelo del texto latino de la Vulgata y de prólogos de san Jerónimo ${ }^{6}$ ). Y lo que es aún más revelador, en dos de las traducciones, la Biblia del Marqués de Santillana y la Biblia de Arragel, contamos con las identidades tanto de los traductores que las llevaron a cabo (el converso Martín de Lucena y el rabino Mosé Arragel respectivamente) como de los destinatarios cristianos que encargaron la realización de dichas traducciones (el Marqués de Santillana y don Luis de Guzmán). En el caso de la Biblia de Arragel contamos además con un prólogo del traductor donde se ofrecen todos los detalles sobre el diseño y el desarrollo final del proyecto ${ }^{7}$.

El objetivo final de este trabajo es determinar el reparto de léxico vernáculo tradicional frente a las innovaciones cultas o modernizantes en cada una de las versiones analizadas y determinar cómo se resuelve en cada caso la problemática cultural que hemos esbozado en los párrafos anteriores. Queremos determinar si los casos de innovación observados son puntuales y dispersos o si hay una intención de actualización particular de algunos traductores que nos permita asociarlos de alguna manera a la corriente pre-humanista de la época, alimentada por la traducción de textos latinos y de otros romances, y que propició la entrada al español de un léxico renovado que dotó a los autores, incluyendo a los traductores bíblicos, de mayores opciones a la hora de expresarse en castellano. Igualmente será interesante observar si algunos traductores muestran mayor resistencia a la innovación, dado el contexto so-

${ }^{5}$ Todas las versiones medievales pueden consultarse en el corpus Biblia Medieval (www. bibliamedieval.es).

${ }^{6}$ En consecuencia no suscribimos la idea defendida por Llamas 1950-1955, pp. LIV-LVI y seguida por otros ( $c f$. Littlefield 1992, pp. XXI) de que existe una división entre biblias hechas para judíos y biblias hechas para cristianos.

${ }^{7}$ Para una exposición detallada de cómo se gestó y ejecutó la Biblia de Arragel así como los pocos detalles biográficos que se conocen de su autor véase Fellous-Rozenblat 1992. 
cio-religioso complejo en el que traducen, y en el que los destinatarios de la traducción no son las propias comunidades tradicionales judías que generan el texto, sino un grupo de nobles intelectuales castellanos claramente abiertos a recibir y usar en sus obras un caudal léxico renovado, en el cual no puede faltar el de la Biblia.

En las páginas que siguen nos centramos en la exploración del léxico de las cuatro Biblias completas traducidas en el siglo XV que conservamos ${ }^{8}$ :

a) Biblia E3: traducción conservada en el códice I.i.3 del Escorial; contiene un romanceamiento completo del canon hebreo seguido de versiones de los Macabeos I y II traducidas a partir del latín. Mientras que la fecha de composición del original perdido da lugar a discusión la copia conservada puede localizarse en la primera mitad del siglo XV.

b) Biblia E7-E5: Los códices escurialenses I.i.7 e I.i.5 se consideran dos volúmenes complementarios que forman un romanceamiento completo del canon hebreo. El primero de estos códices contiene el romanceamiento del Pentateuco y los Profetas Anteriores; por su parte E5 traduce del hebreo los Profetas Posteriores y los Escritos. Se desconoce el traductor o el destinatario de la traducción; los códices fueron copiados en la primera mitad del XV.

c) Biblia del Marqués de Santillana: Biblia traducida por el converso Martín de Lucena para el Marqués de Santillana. En su forma original debió constar de tres volúmenes. El primero no se ha conservado pero el texto que contenía ha sido transmitido en el Pentateuco y los Profetas Anteriores del códice E4. El segundo volumen, con los Profetas Posteriores y algunos escritos se conserva en la Biblioteca Nacional de España con la signatura 10288. El tercero, que contiene los Evangelios y las Epístolas Paulinas traducidos a partir del latín, se ha transmitido en el códice 9556 de la Biblioteca Nacional.

d) Biblia de Arragel: Se trata de la Biblia traducida por Mosés Arragel en colaboración con fray Arias de Encinas por encargo de Luis de Guzmán, maestre de la Orden de Calatrava. Contiene una traducción completa del canon hebreo acompañada de un extenso comentario y numerosas iluminaciones. El original, realizado entre 1422 y 1430, se conserva en la Casa Ducal de Alba (Palacio de Liria, Madrid).

\footnotetext{
${ }^{8}$ Hemos excluido del análisis los romanceamientos parciales transmitidos en los códices E19 (Pentateuco), RAH (Profetas Posteriores) y Oxford (Profetas Anteriores) por dos motivos: primero para facilitar la comparación cuantitativa, usando textos de una extensión similar (alrededor de 500.000 palabras en cada Biblia completa, frente a la extensión mucho menor de las fragmentarias) y en segundo lugar para evitar las distorsiones que pueda ocasionar la distinta distribución de géneros y registros que se da en las biblias incompletas.
} 
En nuestro análisis nos concentramos en el plano léxico ya que este nos permite comparar objetivamente las versiones entre sí y además cuantificar su comportamiento frente a los datos del español general obtenidos en trabajos de carácter cuantitativo o de nuestra propia consulta sobre el Corpus Diacrónico del Español (CORDE). Realizamos nuestro análisis en cuatro fases complementarias:

a) En primer lugar, establecemos la definición de lo que consideramos innovación léxica en cada traductor (es decir, del léxico propio y exclusivo de cada autor) y la definición de lo que consideramos léxico tradicional (es decir, léxico compartido con las demás traducciones) y cuantificamos de modo general dicha innovación (o tradición) en cada versión bíblica (véase el apartado 2).

b) Una vez establecido el compromiso de cada traducción con el léxico tradicional, nos centraremos en la exploración de algunos lemas hebreos seleccionados y de las equivalencias castellanas de los mismos que ofrecen los diferentes romanceamientos estudiados (véase el apartado 3).

c) A continuación analizamos algunos fenómenos de morfología derivativa que, sin abandonar el ámbito léxico, nos mostrarán la aceptación o el rechazo de algunos procesos de innovación estructurales que ocurren a lo largo del siglo XV, yendo más allá de la simple incorporación o rechazo de elementos léxicos particulares. Nos referimos a la formación de derivados con los sufijos innovadores -ísimo, -mente, -ción, -idad frente a soluciones vernáculas tradicionales como -miente, -miento o -ura (véase el apartado 4).

d) Finalmente, llegando al límite de análisis estructural que permite el plano léxico, estudiamos el empleo verbal del participio de presente (creciente, produciente, floreciente, etc.), una construcción léxico-sintáctica que nos permite observar de forma paralela la tensión entre la traducción literal hebraizante tradicional y los usos novedosos latinizantes (véase el apartado 5).

En todos los casos formalizamos una gradación de mayor a menor presencia de innovación (o de tradición) en los diferentes romanceamientos. Una vez examinados todos los fenómenos léxicos y establecidas las jerarquías en el eje de la innovación, nos detenemos en caracterizar las cuatro Biblias analizadas de acuerdo a los datos ofrecidos (véase el apartado 6). 


\section{DISTRIBUCIÓN GENERAL: LÉXICO TRADICIONAL FRENTE A LÉXICO DE AUTOR}

El primer paso para determinar qué romanceamientos bíblicos se apartan o se acercan en mayor medida al léxico bíblico tradicional disponible en el siglo $\mathrm{XV}$ es el establecimiento de una definición objetiva de dicho léxico tradicional. En este trabajo definimos tradición léxica como el conjunto de voces compartidas por todas y cada una de las traducciones bíblicas que se han preservado en el siglo $\mathrm{XV}^{9}$. Hemos excluido del análisis los libros bíblicos traducidos del latín, tanto los libros deuterocanónicos como el Nuevo Testamento y también aquellos libros pertenecientes al canon hebreo cuya traducción se realizó a partir de la Vulgata ${ }^{10}$.

Para establecer el conjunto de voces compartidas por todas las Biblias se ha realizado la concordancia exhaustiva de todos los textos relevantes $^{11}$, y se ha procedido a una normalización gráfica superficial ${ }^{12}$. Una vez igualados, en lo posible, los usos gráficos de los manuscritos, se ha comparado cada una de las formas léxicas de cada traducción con el resto de las versiones y se ha contabilizado el porcentaje de léxico compartido por todos y cada uno de los romanceamientos, lo cual resulta en un índice objetivo de compromiso de cada versión con el léxico tradicional ${ }^{13}$ :

\footnotetext{
${ }^{9}$ No tenemos en cuenta las traducciones anteriores realizadas en el siglo XIII (E8-E6 y la General estoria), primero porque son traducciones realizadas a partir del latín, por lo que pueden incorporar más fácilmente elementos latinos y en segundo lugar para evitar distorsionar los resultados con la introducción en el análisis de un parámetro diacrónico adicional.

${ }^{10}$ Concretamente se han excluido los siguientes libros traducidos del latín: Macabeos I-II de E3; Salmos, Tobías, Judit, Sabiduría, Eclesiástico y Macabeos I-II de E4; y el Nuevo Testamento y Epístolas Paulinas de Martín de Lucena (que es parte de la Biblia de Santillana). Excluimos además otros manuscritos (Ajuda, Évora, RAH, etc.) que reflejan el mismo texto transmitido en las cuatro Biblias analizadas pero en copias de menor calidad. Para la determinación de las seis traducciones originales del siglo XV, véase nuestro trabajo Pueyo Mena, Enrique-Arias 2013.

${ }^{11}$ A partir de los textos paleográficos recogidos en el corpus Biblia Medieval (Enrique-Arias 2008). Una concordancia similar (sin exclusión de ningún libro bíblico) puede encontrarse en Gago-Jover, Enrique-Arias, Pueyo Mena 2013.

${ }^{12}$ En este caso nos referimos a una normalización superficial con la que hemos tratado de igualar los usos gráficos más importantes: normalización de las grafías $i / j / y$ y $u / v$ dejando $i / u$ para los usos vocálicos y $j / v$ para los consonánticos, normalización de $(s) c^{e i}$ y $(s) c^{e i}$, unificación de la alternancia $m / n$ ante nasal en favor de $m$, de qua en $c u a$, reducción de las consonantes dobles $n n$ a $\tilde{n}$, simplificación de $m m, f f, t t$, y de $r r$ en posición inicial, y de grupos como $p h$ a $f$ y th a $t$. Lógicamente hay variantes gráficas que no se han podido igualar automáticamente, aunque ciertamente suponen las grafías más innovadoras de cada códice, por lo que excluirlas del conjunto léxico tradicional tampoco supone una gran distorsión (véase una discusión de los fenómenos de innovación gráfica en la Biblia de Arragel a continuación).

${ }^{13}$ Aunque, como ya hemos mencionado, no incluimos en el análisis comparativo las traducciones parciales contenidas en los códices E19 y Oxford consignamos a título meramente orientativo sus porcentajes de léxico común: E19 90,1\% (105.647 / 117.278); Oxford 88,4\% $(88.830 / 100.436)$.
} 
Tabla 1. Léxico tradicional compartido [Porcentaje de léxico que aparece en todas las Biblias]

\begin{tabular}{|l|c|c|c|}
\hline $\begin{array}{c}\text { Traducciones Bíblicas } \\
\text { del s. XV }\end{array}$ & $\begin{array}{c}\mathbf{N}^{\circ} \text { de formas } \\
\text { comunes }\end{array}$ & $\begin{array}{c}\mathbf{N}^{\circ} \text { total de formas en } \\
\text { la Biblia }\end{array}$ & $\begin{array}{c}\text { \% de léxico } \\
\text { tradicional }\end{array}$ \\
\hline E3 & 455.508 & 502.342 & $90,7 \%$ \\
\hline E7/E5 & 475.665 & 527.912 & $90,1 \%$ \\
\hline Biblia de Santillana & 451.799 & 506.611 & $89,1 \%$ \\
\hline Biblia de Arragel & 455.508 & 566.581 & $80,4 \%$ \\
\hline
\end{tabular}

Mediante los datos de la Tabla 1, podemos establecer una primera gradación o jerarquía de compromiso de las versiones con el léxico bíblico tradicional común del siglo $\mathrm{XV}$ :

$$
\begin{aligned}
& \text { +innovador } \rightarrow \rightarrow \rightarrow \rightarrow \rightarrow \rightarrow \rightarrow \rightarrow \rightarrow \rightarrow \rightarrow+\text { tradicional } \\
& \text { Arragel }(80,4 \%)<\text { Santillana }(89,1 \%)<\text { E7/E5 }(90,1 \%)<\text { E3 }(90,7 \%)
\end{aligned}
$$

Del mismo modo se ha contabilizado el fenómeno opuesto, es decir, aquellas formas léxicas que aparecen de manera exclusiva en una sola de las traducciones pero nunca en las demás, lo cual nos ofrece un índice de léxico personal de autor y por lo tanto de innovación léxica sobre la tradición ${ }^{14}$ :

Tabla 2. Léxico innovador no compartido [Porcentaje de léxico que no aparece en ninguna otra Biblia]

\begin{tabular}{|l|c|c|c|}
\hline $\begin{array}{c}\text { Traducciones Bíblicas } \\
\text { del s. XV }\end{array}$ & $\begin{array}{c}\mathbf{N}^{\circ} \text { de formas } \\
\text { exclusivas }\end{array}$ & $\begin{array}{c}\mathbf{N}^{\circ} \text { total de formas en } \\
\text { la Biblia }\end{array}$ & $\begin{array}{c}\text { \% de léxico } \\
\text { innovador }\end{array}$ \\
\hline E3 & 12.828 & 502.342 & $2,6 \%$ \\
\hline E7/E5 & 14.713 & 527.912 & $2,8 \%$ \\
\hline Biblia de Santillana & 16.578 & 506.611 & $3,3 \%$ \\
\hline Biblia de Arragel & 29.050 & 566.581 & $5,1 \%$ \\
\hline
\end{tabular}

La Tabla 2 nos permite establecer una gradación inversa a la anterior $^{15}$, es decir, la jerarquía de innovación léxica general de cada una de las Biblias analizadas:

\footnotetext{
${ }^{14}$ En este caso tenemos 2,6\% para E19 (3.061 / 117.278) y 2,8\% para Oxford (2.803 / 100.436).

${ }^{15}$ Como puede observarse los porcentajes en ambas jerarquías no son complementarios, es decir hay un porcentaje residual (entre el 14,5\% en la Biblia de Arragel y el 6,7\% de E3) que corresponde al léxico que comparten algunas de las Biblias entre sí, pero que no es común a todas ellas.
} 
+tradicional $\rightarrow \rightarrow \rightarrow \rightarrow \rightarrow \rightarrow \rightarrow \rightarrow \rightarrow \rightarrow \rightarrow$ +innovador

E3 $(2,6 \%)<$ E7/E5 $(2,8 \%)<$ Santillana $(3,3 \%)<$ Arragel $(5,1 \%)$

Al tratarse de un texto altamente sacralizado, el conservadurismo léxico es un fenómeno ciertamente esperable, especialmente teniendo en cuenta que las traducciones fueron realizadas por miembros de una comunidad judía fuertemente tradicional, apegada a usos religiosos y cotidianos que tenían como centro el texto original de la Biblia, y en la que el proceso de traducción al vernáculo se usaba como herramienta de estudio desde la infancia, no solo para el análisis exegético, sino también para la comprensión lingüística del hebreo ${ }^{16}$. Por todo ello, no es extraño que los valores que resultan del análisis de E3, E7/E5 y Santillana sean muy cercanos.

Llama la atención, sin embargo, el salto cuantitativo que observamos en la Biblia de Arragel, tanto en el elevado número de innovaciones léxicas ( 29.050 o $5,1 \%)$, como en su relativa falta de conservación de léxico tradicional (455.508 o 80,4\%). Un aspecto cultural muy sobresaliente en esta Biblia es el uso frecuente de grafías latinizantes, fenómeno que no se observa en el resto de los códices (a excepción de RAH, claramente emparentado con la Biblia de Arragel). Por ejemplo, Arragel es el único que usa Israhel en lugar de Israel (828 veces) o formas gráficas latinizantes del tipo lux (92), herba (9), pax (154) en alternancia con las tradicionales luz (17), yerva (36), paz (87), entre otras, siguiendo a veces los usos gráficos de la Vulgata. Dado que no hemos lematizado las entradas léxicas, estos usos gráficos cultistas (que podrían reflejar una intención de lectura latinizante) no quedan eliminados mediante una normalización superficial como la que hemos efectuado para este trabajo y muestran en sí mismos un afán más modernizador de la Biblia de Arragel, afán que como veremos en los siguientes apartados, se refleja en otros aspectos menos superficiales de la lengua.

\section{ANÁLISIS DE LA TRADUCCIÓN DE ALGUNOS LEMAS HEBREOS}

En un trabajo anterior realizamos el análisis de las traducciones castellanas de 28 lemas hebreos a lo largo de todos los romanceamientos bíblicos traducidos del hebreo durante el siglo $\mathrm{XV}^{17}$. El propósito de contabilizar las más de 20.000 correspondencias castellanas de dichos lemas hebreos en los nueve códices medievales cuatrocentistas fue en aquella ocasión determinar

\footnotetext{
${ }^{16}$ Para una explicación del método de enseñanza tradicional en torno a la traducción del texto bíblico en las comunidades judías, véase Bunis 1996.

${ }^{17}$ Pueyo Mena, Enrique-Arias 2013.
} 
el número de traducciones reales que contenían dichos códices y detectar la presencia de un mismo traductor en cada uno de ellos (o de más de un traductor en una misma unidad codicológica). Al realizar dicho análisis descubrimos diferencias significativas entre las diversas traducciones en cuanto a la aparición desigual en cada una de ellas de innovaciones léxicas sobre la base del vocabulario bíblico tradicional que todas compartían.

Analizando el vocabulario que se presenta en la Tabla 3, podemos establecer una tipología de voces castellanas empleadas para traducir los lemas hebreos de la columna izquierda:

a) Voces tradicionales que representan el vocablo de empleo común a lo largo de la Edad Media (fonsado, hueste, mayoral, vara, ropa, paño, hueste, real, bestia, fabla, diestra), incluyendo arcaísmos o léxico especializado que se emplea muy raramente fuera de estas traducciones bíblicas (alsación, barragán, remanecer, aborrir).

b) Voces patrimoniales innovadoras que van sustituyendo a vocablos tradicionales o que entran en competencia sinonímica con ellos a lo largo de la historia de la lengua: príncipe/capitán/condestable frente a mayoral/ cabdillo, o gentelpueblo en lugar de compaña, lengua/lenguaje en lugar de fabla, dexar/quedar frente a remanecer, vestimenta en lugar de ropa/paño, corriente frente a arroyo/río, o derecha/izquierda en competencia con diestra/siniestra ${ }^{18}$.

c) Cultismos innovadores o latinismos que comienzan a entrar en la lengua en el siglo XV. Algunos de ellos han permanecido en castellano, normalmente con un sentido especializado (holocausto, olio, precepto, concilio, potente, cátedra, primogénito, abominación, congregación, república, setentrión, institución, administración) y otros no tuvieron éxito y desaparecieron pronto (animalia, estrenuo, holocausta, colación, aquilón).

Las voces de los grupos $b$ y $c$, es decir, aquellas que consideramos innovadoras frente al fondo común empleado por todos los romanceamientos, están señaladas en negrita en la Tabla 3. Además, para facilitar la comparación, hemos sombreado las celdas de la tabla que incluyen dichos usos innovadores. En cuanto a la distribución de voces tradicionales e innovadoras en cada Biblia podemos sacar las siguientes conclusiones:

a) La Biblia E3 presenta un doble conservadurismo: en primer lugar, muestra muy pocas variantes o sinónimos a la hora de traducir un lema hebreo a lo largo de toda la Biblia; y, en segundo lugar, muestra un grado de fidelidad muy alto a las voces más tradicionales o antiguas.

\footnotetext{
${ }^{18}$ Véase la Tabla 5 del Apéndice I para una exploración cuantitativa de la implantación de estas voces patrimoniales en la lengua según los datos obtenidos en CORDE.
} 
b) La Biblia E7/E5 muestra un estadio intermedio de innovación léxica: no presenta demasiadas voces modernizantes, aunque sí algunas, pero se aleja del conservadurismo de E3 al emplear numerosos sinónimos patrimoniales, algunos de ellos tan medievales como los usados en E3 ( $c a b$ dillo, corte, batalla, real, alcavela, arambre, encomendança, engaño), y otros decididamente más modernos (vestimenta, olio, corriente, mentira, gente).

c) Martín de Lucena, traductor de la Biblia de Santillana, se nos muestra como un renovador comprometido que incorpora voces más modernas (mentira, derecha, etc.), evita sistemáticamente algunas muy tradicionales (remanecer) y emplea numerosos latinismos, aunque debidamente integrados en la lengua castellana (holocausto, olio, precepto, concilio, potente, estrenuo, institución, etc.). Por otro lado, Lucena, al igual que el traductor de E3, se atiene en mayor medida que E7/E5 o que Arragel a la tradición de traducción judía de utilizar el mismo vocablo romance para traducir todas las apariciones de la misma palabra hebrea, evitando el uso de sinónimos para enriquecer estilísticamente el texto. El motivo sería el deseo de un mayor apego al lema hebreo subyacente ya que el uso de dichas variantes podría distorsionar su significado.

d) La Biblia de Arragel, al igual que la anterior, se decanta claramente por lecturas innovadoras, pero da un paso más allá de Lucena al incorporar más latinismos, los cuales en algunos casos están menos adaptados al castellano de la época (fortíssimo, aquilón, holocausta). Al igual que E7/ E5 muestra cierta tendencia a usar mayor número de sinónimos para cada lema hebreo ${ }^{19}$.

${ }^{19}$ Para los detalles numéricos exactos de cada lema en todas las Biblias castellanas puede consultarse nuestro trabajo: Pueyo Mena, Enrique-Arias 2013. 
Tabla 3. Distribución de traducciones tradicionales e innovadoras en 28 lemas hebreos en toda Biblia

\begin{tabular}{|c|c|c|c|c|}
\hline Lema & E3 & E5/E7 & Santillana & Arragel \\
\hline ŝaba & $\begin{array}{c}\text { fonsado / } \\
\text { hueste / com- } \\
\text { paña / sabaod } \\
\text { / guerra }\end{array}$ & $\begin{array}{c}\text { gente / batalla } \\
\text { / hueste / real / } \\
\text { corte / alcavela / } \\
\text { sabaod }\end{array}$ & hueste / sabaod & $\begin{array}{l}\text { hueste / fonsado } \\
\text { / cavallería / } \\
\text { sabaod }\end{array}$ \\
\hline $\begin{array}{l}\text { sar / } \\
\text { nasí }\end{array}$ & mayoral & $\begin{array}{l}\text { cabdillo / cabece- } \\
\text { ra / alguazil / ma- } \\
\text { yoral / príncipe / } \\
\text { grnade / capitán }\end{array}$ & $\begin{array}{l}\text { príncipe / capi- } \\
\text { tán / cavallero / } \\
\text { cabecera }\end{array}$ & $\begin{array}{l}\text { príncipe / cava- } \\
\text { llero / mayoral }\end{array}$ \\
\hline ‘olá & alsación & $\begin{array}{l}\text { alsación / sacri- } \\
\text { ficio } \\
\end{array}$ & holocausto & holocausta \\
\hline $\begin{array}{l}\text { maté / } \\
\text { šébet }\end{array}$ & vara & $\begin{array}{c}\text { blago / piértego } \\
\text { / verdugo / palo } \\
\text { / lança / mando / } \\
\text { saeta / tenimiento } \\
\text { / venablo / verga } \\
\text { / yugo }\end{array}$ & $\begin{array}{l}\text { blago / verga / } \\
\text { vara }\end{array}$ & $\begin{array}{l}\text { blago / verga / } \\
\text { ceptro }\end{array}$ \\
\hline bégued & ropa / paño & $\begin{array}{c}\text { paño / ropa / } \\
\text { vestidura / vesti- } \\
\text { menta } \\
\end{array}$ & paño & paño / vestimenta \\
\hline šemen & $\begin{array}{l}\text { azeite / grosu- } \\
\text { ra / bálsamo }\end{array}$ & $\begin{array}{c}\text { azeite / olio / } \\
\text { grueso / ungüento }\end{array}$ & $\begin{array}{c}\text { olio / azeite / } \\
\text { grueso / ungüento }\end{array}$ & $\begin{array}{c}\text { olio / grueso / } \\
\text { ungüento }\end{array}$ \\
\hline behemá & $\begin{array}{c}\text { bestia / } \\
\text { cuatropea / } \\
\text { animalia } \\
\end{array}$ & $\begin{array}{l}\text { bestia / cuatropea } \\
\text { / animalia }\end{array}$ & bestia / animalia & $\begin{array}{l}\text { bestia / res / ani- } \\
\text { malia / ganado }\end{array}$ \\
\hline miŝvá & $\begin{array}{l}\text { mandamiento } \\
\text { / mandado }\end{array}$ & $\begin{array}{l}\text { encomienda / } \\
\text { encomendança / } \\
\text { mandamiento }\end{array}$ & $\begin{array}{c}\text { precepto / manda- } \\
\text { miento / enco- } \\
\text { mienda } \\
\end{array}$ & $\begin{array}{l}\text { mandamiento / } \\
\text { mandado }\end{array}$ \\
\hline safá & fabla / palabra & $\begin{array}{c}\text { lenguaje / } \\
\text { lengua }\end{array}$ & $\begin{array}{c}\text { lengua / lenguaje } \\
\text { / fabla } \\
\end{array}$ & $\begin{array}{c}\text { lengua / sermón / } \\
\text { palabra }\end{array}$ \\
\hline ‘edá & $\begin{array}{l}\text { compaña / } \\
\text { concejo }\end{array}$ & compaña & $\begin{array}{l}\text { gente / pueblo / } \\
\text { compaña }\end{array}$ & $\begin{array}{c}\text { gente / pueblo } \\
\text { / sinagoga / } \\
\text { congregación / } \\
\text { compaña } \\
\end{array}$ \\
\hline cahal & compaña & $\begin{array}{l}\text { compaña / ayun- } \\
\text { tamiento }\end{array}$ & $\begin{array}{l}\text { pueblo / concilio / } \\
\text { ayuntamiento }\end{array}$ & $\begin{array}{c}\text { colación / gente } \\
\text { / egleja / congre- } \\
\text { gación / repú- } \\
\text { blica } \\
\end{array}$ \\
\hline zebah & sacrificio & sacrificio & Sacrificio & sacrificio \\
\hline
\end{tabular}




\begin{tabular}{|c|c|c|c|c|}
\hline guibor & barragán & barragán & $\begin{array}{l}\text { potente / } \\
\text { estrenuo }\end{array}$ & $\begin{array}{l}\text { barragán / pode- } \\
\text { roso / fortíssimo } \\
\text { / fuerte }\end{array}$ \\
\hline ŝafón & meridión & $\begin{array}{l}\text { çafón / seten- } \\
\text { trión / occidente }\end{array}$ & setentrión & $\begin{array}{c}\text { aquilón / ponien- } \\
\text { te / setentrión }\end{array}$ \\
\hline nehóšet & cobre / latón & $\begin{array}{c}\text { arambre / cobre } \\
\text { / latón / azero / } \\
\text { fierro }\end{array}$ & cobre / azero & $\begin{array}{c}\text { cobre / arambre / } \\
\text { fierro }\end{array}$ \\
\hline yamín & diestra & diestra & $\begin{array}{c}\text { derecha / diestra / } \\
\text { manderecha }\end{array}$ & diestra \\
\hline kisé & silla & silla & cátedra / silla & $\begin{array}{c}\text { silla / cátedra / } \\
\text { trono }\end{array}$ \\
\hline naḥal & arroyo / río & $\begin{array}{c}\text { río / corriente / } \\
\text { arroyo }\end{array}$ & río / arroyo & río / arroyo \\
\hline par & toro & novillo / toro & toro & toro \\
\hline [ni]šar & $\begin{array}{c}\text { quedar / } \\
\text { fincar/ rema- } \\
\text { necer } \\
\end{array}$ & $\begin{array}{l}\text { quedar / dexar / } \\
\text { remanecer }\end{array}$ & quedar / dexar & $\begin{array}{c}\text { remanecer / } \\
\text { quedar-dexar }\end{array}$ \\
\hline ḥoc & fuero & $\begin{array}{c}\text { fuero / constum- } \\
\text { bre }\end{array}$ & $\begin{array}{c}\text { fuero / ración / } \\
\text { institución }\end{array}$ & $\begin{array}{l}\text { fuero / ración / } \\
\text { administración }\end{array}$ \\
\hline koah & fuerça & fuerça & fuerça / potencia & fuerça \\
\hline bejor & \begin{tabular}{|c|} 
mayor / pri- \\
mero / primo- \\
génito \\
\end{tabular} & $\begin{array}{l}\text { primogénito / } \\
\text { mayor / primero }\end{array}$ & primogénito & primogénito \\
\hline to`ebá & $\begin{array}{c}\text { aborr- / mal- } \\
\text { dad } \\
\end{array}$ & $\begin{array}{l}\text { aborr- / heregía / } \\
\text { creencia / maldad }\end{array}$ & abominación & $\begin{array}{c}\text { abominación / } \\
\text { aborr- }\end{array}$ \\
\hline šéquer & fals- & $\begin{array}{c}\text { fals- / engaño / } \\
\text { balde / traición / } \\
\text { mentir- }\end{array}$ & mentir- & fals- /mentir- \\
\hline kebes & carnero & carnero & carnero & cordero / carnero \\
\hline
\end{tabular}

Por lo tanto podemos establecer a partir de la tabla una jerarquía de innovación en la selección léxica realizada por los diferentes traductores a lo largo de todos los libros bíblicos:

$$
\begin{aligned}
& \text { +tradicional } \rightarrow \rightarrow \rightarrow \rightarrow \rightarrow \rightarrow \rightarrow \rightarrow \rightarrow \rightarrow \rightarrow \text { +innovador } \\
& \text { E3 }(1)<\text { E7/E5 (10) }<\text { Santillana (16) < Arragel (16) }
\end{aligned}
$$

Situamos la versión de Arragel como la más innovadora por su uso de formas latinizantes menos adaptadas al castellano. 


\section{MORFOLOGÍA DERIVATIVA}

Más allá de la selección de los cultismos o de las formas patrimoniales más modernas que acabamos de analizar, nos interesa determinar el compromiso de renovación lingüística de cada una de las traducciones en ámbitos más estructurales de la lengua. Sin abandonar el plano léxico, nos centramos en este apartado en el análisis de algunos procesos de morfología derivativa.

\subsection{Dos sufijos decididamente innovadores: -ísimo y -mente}

Comenzamos por dos sufijos derivativos que son característicos del siglo XV por su impronta particularmente cultista: -ísimo y -mente.

En cuanto al sufijo -ísimo (<-ISSIMUS), se utiliza para la creación del superlativo absoluto o sintético. En el paso del latín a las lenguas romances, el sufijo latino se perdió casi completamente y no se reincorporó a los diferentes romances hasta el siglo XV. En castellano, de hecho, esta reincorporación se realiza de forma más tardía que en italiano; por ejemplo, Jörnving, Serradilla Castaño o L. Pons Rodríguez ${ }^{20}$ analizan la evolución de los superlativos en -ísimo y comprueban que su implantación en el siglo XV es todavía escasa: autores como Juan de Mena o el Marqués de Santillana apenas lo emplean, e incluso Villena, siendo un autor que traduce literalmente del latín, lo incorpora en muy pocas ocasiones. Serradilla Castaño destaca que en el siglo XVI, época en la que se consolida esta construcción, es aún un momento de experimentación y su uso constituye, en gran medida, un esfuerzo latinizante, una forma aún no asimilada realmente por el idioma ${ }^{21}$. Efectivamente, en una inspección cuantitativa Zieliński confirma que hasta los siglos XVI y XVII no se consolida definitivamente en la lengua ${ }^{22}$.

En el caso concreto de las Biblias medievales el uso del sufijo refleja de nuevo la jerarquía de innovación que hemos presentado anteriormente:

+tradicional $\rightarrow \rightarrow \rightarrow \rightarrow \rightarrow \rightarrow \rightarrow \rightarrow \rightarrow \rightarrow \rightarrow$ +innovador

-ísimo: $\mathrm{E} 3=\mathrm{E} 7 / \mathrm{E} 5$ (0 casos) $<$ Santillana $(3$ casos $)<$ Arragel $(233$ casos $)$

${ }^{20}$ Jörnving 1962; Serradilla Castaño 2005; Pons Rodríguez 2012, en prensa.

${ }^{21}$ Serradilla Castaño 2005, p. 360.

${ }^{22}$ Según Zieliński 2013, p. 106, la distribución concreta de los 606 casos que ocurren en CORDE es la siguiente: XII $(1,49 \%)$, XIV $(4,46 \%)$, XV $(15,84 \%)$, XVI $(28,71 \%)$, XVII $(49,5 \%)$. 
En la Biblia de Santillana encontramos tres casos adicionales en las rúbricas introductorias o en los colofones de los libros traducidos del latín (el mismo fenómeno ocurre en el Nuevo Testamento de la Biblia de Santillana, no incluido en este estudio, en el que hay 10 casos en las rúbricas y ninguno en el texto bíblico):

Proverbios del gloriosíssimo sabio, príncipe e rey de Israel Salamón.

Aquí comiença el libro de la Sabiduría del gloriosíssimo sabio rey de Israel Salomón.

Aquí se acaba el libro de los Proverbios de Salamón començante en verdad, demediante en amor de aquella, feneciente por la gloriosíssima noticia de aquella.

Pero también encontramos tres casos en los que Martín de Lucena utiliza el superlativo absoluto dentro del texto bíblico. Dos de ellos podrían explicarse por el influjo directo de la Vulgata:

Et ipse aedificavit civitatem potentissimam quam appellavit Igbathanis "E él edificó una cibdat potentíssima, la cual llamó Igbatanis." (Jdt 1, 1)

non adaequabitur ei topazium de Aethiopia nec tincturae mundissimae conponetu "non se compara con ella la esmeralda de India, con el puríssimo oro non se estima." (Job 28:19).

Pero no el tercero:

potens es Domine "o excelentíssimo Señor" $($ Sal 98,9$)$

Por su parte, Arragel se presenta como un innovador muy atrevido, teniendo en cuenta que otros autores castellanos de la época, e incluso posteriores, no incorporan el superlativo absoluto sintético o lo hacen de forma muy esporádica. Podemos atribuir la mitad de los casos al influjo directo de la Vulgata (en 76 versículos):

auro mundissimo "oro puríssimo" (Éx 25, 11)

inimico meo potentissimo "enemigo potentíssimo" (Sam2 22, 18)

similis Altissimo "semejaré al Altíssimo" (Isa 14,14)

si fortitudo quaeritur robustissimus est "si por fuerça es cierto fortíssimo" $($ Job 9, 19) 
Sin embargo, el resto de los usos innovadores de Arragel son de cosecha propia (en 117 versículos), como muestran los siguientes ejemplos:

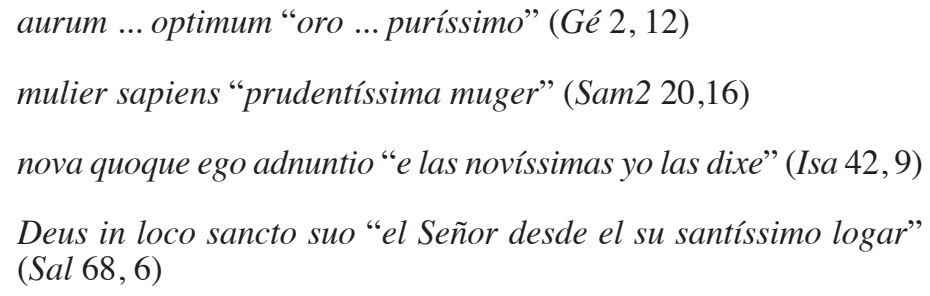

Si analizamos el prólogo y la extensa glosa que acompaña a la traducción bíblica, en donde Arragel se expresa más libremente como autor, encontramos más de 300 casos de uso del sufijo -ísimo, lo cual nos asegura que el superlativo absoluto latino formaba parte del castellano culto y personal de Mosé Arragel. Parece que Arragel encontró en el -ISSIMUS de la Vulgata un mecanismo satisfactorio para la expresión no perifrástica del superlativo y al parecer se adelanta a otros autores en la incorporación del mismo a la creación literaria.

Al igual que en la expresión del superlativo, la historia de la incorporación al castellano del sufijo -mente para la adverbialización de adjetivos es un proceso de corte cultista del registro literario de la lengua. Company ha estudiado recientemente, mediante datos cuantitativos, la pérdida a mediados del XIV de la variante vernácula diptongada -miente para esta función y el ascenso en textos literarios, pero no en otros ámbitos de la lengua, de la variante no diptongada, a partir de mediados del siglo XIV ${ }^{23}$. En definitiva la adverbialización con -mente es un fenómeno cultista que cobra fuerza a mediados del siglo XIV, que queda restringido hasta el siglo XVII al registro literario y que incluso en la actualidad sigue siendo un recurso estilístico propio de la lengua escrita con muy poca expresión en el español oral ${ }^{24}$. Es decir, se nos presenta, por lo tanto, como un recurso lingüístico muy poco tradicional. En el caso de las Biblias se cumple de nuevo la jerarquía de innovación en las diferentes versiones:

$$
\text { +tradicional } \rightarrow \rightarrow \rightarrow \rightarrow \rightarrow \rightarrow \rightarrow \rightarrow \rightarrow \rightarrow \rightarrow \text { +innovador }
$$

-mente: E3 (5) < E7/E5 (44) < Santillana (119) < Arragel (130)

\footnotetext{
${ }^{23}$ Company 2012.

${ }^{24}$ Company 2012,pp. 17 y ss.
} 
Es cierto que cuando el adjetivo que se quiere adverbializar es común en la lengua, todas las Biblias presentan la formación con -mente en numerosas ocasiones, como muestra el siguiente ejemplo del libro de Daniel $(6,21)$ :

E3: $\quad$ tu Dios que tú servías continuamente ¿pudo escaparte de los leones?

E7/E5: aquel tu Dios al cual tu sirves sanamente ¿á te podido escapar de los leones?

Santillana: tu Dios a quien sirves continuamente ¿síte pudo escapar de los leones?

Arragel: $\quad$ el tu Dios aquel a quien tú continuamente sirves ¿si á podido librarte de los leones?

Sin embargo, en la Biblia E3 los casos de innovación real de autor, fuera de la tradición bíblica, son mínimos. He aquí dos de los cinco casos que hemos podido recoger:

E asentóse pláceramente ant'el camino $(G e ́ 38,14)$

E la tierra non se venderá traspasadamente $(L e 25,23)$

De las todas las formas exclusivas y, por lo tanto, innovadoras de E7/ E5 podemos listar las siguientes:

E7/E5: acuciosamente, airadamente, amargosamente, apaziguadamente, apresurosamente, argullosamente, aseguradamente, conteneadamente, cubiertamente, cutianamente, enceladamente, ensalçadamente, eternamente, lealmente, legítimamente, maliciosamente, neciamente, perdurablemente, sabiamente, sobejanamente, sosegadamente.

Mientras que en las Biblias de Santillana y sobre todo en la Biblia de Arragel podemos citar numerosas formas de uso exclusivo e innovador de sus autores, como se muestra en los siguientes listados:

Santillana: abastantemente, afiuzadamente, agradablemente, amargamente, añadidamente, angostamente, arrebatadamente, aventajadamente, cautelosamente, cercanamente, claramente, declaradamente, deliciosamente, entendidamente, fortificadamente, judaicamente, junctamente, liberalmente, limitadamente, livianamente, palpablemente, personalmente, plaziblemente, prestamente, segundariamente, solícitamente, sosamente, trinamente, vanamente, vazíamente, uniformemente. 
Arragel: abscondidamente, articulosamente, artificialmente, begninamente, blandamente, brevemente, cortésmente, demasiadamente, diligentemente, durísimamente, ecualmente, enfiestamente, enteramente, espantosamente, espesamente, fermosamente, festinadamente, finalmente, furtíbilemente, glorificadamente, gruesamente, intrínsecamente, largamente, locamente, montamente, noblemente, ordenadamente, plenariamente, purísimamente, quebrantadamente, quedamente, rebatadamente, rectamente, regidientemente, reciamente, ricamente, secretariamente, simplícitamente, singularmente, soberviosamente, sobitañamente, solitariamente, sotilmente.

\subsection{Sufijos derivativos en competencia: tradición (-ura, -miento) frente a innovación (-ción, -idad)}

Siguiendo con la búsqueda de innovaciones estructurales en la formación del léxico utilizado en las traducciones bíblicas, hemos analizado el comportamiento de cuatro sufijos castellanos cuya función es la de crear sustantivos abstractos a partir de verbos o adjetivos. Comparamos dos sufijos innovadores (-ción e -idad), con cierta presencia en la historia de la lengua anterior al siglo $\mathrm{XV}^{25}$, con dos sufijos más tradicionales, pero que cumplen la misma función que los anteriores (-ura y -miento) ${ }^{26}$.

La creación de sustantivos deverbales mediante procesos de morfología derivativa en las Biblias medievales es uno de los recursos habituales de los traductores judíos, ya que les permite transmitir la relación que existe en el hebreo original entre los verbos y sustantivos que derivan de la misma raíz hebrea (algo muy frecuente en el hebreo bíblico). Por ejemplo, el verbo hebreo nibhalú "se turbaron" y el sustantivo behalot "turbaciones" tienen en común la misma raíz hebrea \.ה. (b.h.l). Los traductores representan el hecho de que la misma raíz hebrea se encuentre en el verbo y en el sustantivo originales creando un derivado deverbal; si para traducir el nibhalú de Gé 45:3 tenemos torvarse (E3), turbarse (Arragel) o conturbarse (E7/E5) el sustantivo

\footnotetext{
${ }^{25}$ A falta de estudios cuantitativos que nos aseguren el carácter innovador de ambos sufijos hemos realizado un análisis preliminar en CORDE: -ción aumenta considerablemente su uso en el s. XV (se multiplica por 1,7 respecto al XIV y por 3,6 respecto al XIII) e -idad aumenta también considerablemente (se multiplica su uso por 1,9 respecto al XIV y por 2,5 respecto al XIII).Véanse los datos numéricos en la Tablas 1-2 del Apéndice I.

${ }^{26} \mathrm{~A}$ falta de estudios cuantitativos que nos aseguren el carácter tradicional de ambos sufijos hemos realizado un análisis preliminar en CORDE. Ambos sufijos caen del XIII al XIV aunque luego se recuperan en el XV. -ura se recupera en menor medida quedando su uso en el siglo XV por debajo del siglo XIII, -miento se recupera en mayor medida (seguramente ocupando algunos espacios funcionales abandonados por - ura), lo cual no es sorprendente ya que sigue siendo productivo en español moderno. Véanse los datos numéricos en la Tablas 3-4 del Apéndice I.
} 
behalot en Jer 15:8 es traducido atorvamientos (E3), turbaciones (Arragel) o turbamientos (E7/E5), es decir, mediante el uso de los sufijos -miento o -ción. Por lo tanto, al analizar el uso de unos u otros sufijos, tratamos de examinar cuál es el tratamiento linguístico que presenta cada versión (de más conservador a más innovador) para construir estos sustantivos sobre la base tradicional del método de traducción (sustantivos que por ese motivo representan en sí mismos en muchas ocasiones neologismos exclusivos de estas traducciones). Comenzamos con el análisis de los sufijos innovadores propuestos:

-ción (<-TIONEM) permite la creación de sustantivos deverbales de acción, efecto, o resultado (nomina actionis). Como hemos visto en el ejemplo, el resultado o efecto de turbarse puede ser la "turbación" (Arragel, Jer 15, 8), así como el de perdonar es la "perdonación" (E19, Lev 23, 27), de tentar es la "tentación" (Santillana, Éx 17,7) o de aborrer o aborrecer es la "aborrición" (E5/E7, Det 12,31), etc.

-idad (<-ITATEM) permite la creación de sustantivos de-adjetivales para expresar cualidades abstractas (nomina qualitatis). Así, la cualidad de ser falso es la "falsedad" (E3, Éx 23, 7), de ser simple es la "simplicidad" (Arragel, Job 2, 9), de ser terrible es la "terribilidad" (E4, Det 4,34) o de ser virgen es la "virginidad" (E7/E5, Det 22,15).

Los resultados que encontramos en las Biblias se resumen en la siguiente tabla:

Tabla 4. Sufijos innovadores -ción e -idad [Léxico único en cada Biblia]

\begin{tabular}{|l|c|c|c|}
\hline \multicolumn{1}{|c|}{ Biblias } & -cion(es) & -idad(es) & TOTAL \\
\hline E3 & 46 & 25 & 71 \\
\hline E7/E5 & 177 & 14 & 191 \\
\hline Santillana & 470 & 106 & 576 \\
\hline Arragel & 718 & 77 & 795 \\
\hline
\end{tabular}

Tomando ambos recursos innovadores de forma conjunta volvemos a observar que se cumple de nuevo la jerarquía propuesta:

+tradicional $\rightarrow \rightarrow \rightarrow \rightarrow \rightarrow \rightarrow \rightarrow \rightarrow \rightarrow \rightarrow \rightarrow$ +innovador

-ción/-idad: E3 (71) < E7/E5 (191) < Santillana (576) < Arragel (795)

Efectivamente en el caso de -ción se mantiene con exactitud la jerarquía de menor a mayor innovación en las traducciones: E3 (46) < E7/E5 (177) $<$ Santillana (470) < Arragel (718). Mientras que en -idad las Biblias más tradicionales invierten sus posiciones (E3 prefiere -idad más que E7/E5) y las más innovadoras también (Lucena prefiere -idad más que Arragel): E7/E5 
(14) < E3 (25) < Arragel (77) < Santillana (106). Esta distribución nos invita a pensar que -ción refleja una mayor innovación relativa que -idad, tal y como lo indicaban los datos extraídos de CORDE (véase nota 20).

Respecto a los dos sufijos que hemos caracterizado como más tradicionales:

-ura (<-TURA, -URA) se utiliza para crear sustantivos tanto deverbales como de-adjetivales. Es decir, este sufijo puede derivar sustantivos tanto de participios de pasado verbales como de adjetivos plenos y por lo tanto habilita la creación de sustantivos en dos frentes semánticos: por un lado pueden expresar el resultado abstracto de la acción del verbo: el resultado de mojarse es estar mojado y de ahí se deriva una "mojadura" (E19, Éx 16, 13), de menear $>$ meneado resulta una "meneadura" (E3, Lev 9, 21), de mesar > mesado se deriva una "mesadura" (Santillana, Lev 21,5) o de calçar $>$ calçado se deriva una "calçadura" (E5/E7, Det 33, 25). Y por otro lado construyen sustantivos que indican la cualidad abstracta del adjetivo o del participio de cual derivan: de enconado obtenemos "enconadura" (Arragel, Lev 13, 55), de salido tenemos "salidura" (E7/E5, Núm 34, 5), o del adjetivo triste se deriva "tristura" (E3, Gén 27, 41) y de preto se deriva "pretura" (Arragel, Ece 11, 10).

-miento (< MENTUM) cumple exactamente la misma función que veíamos en -ción, es decir, la creación de sustantivos abstractos deverbales para expresar resultado o efecto. De hecho encontramos dobletes para muchos de los ejemplos en -ción que veíamos anteriormente: de la acción de turbarse tenemos no solo "turbación" sino también "turbamiento" (E7/E5, Jer 15, 8), de perdonar tenemos tanto "perdonación" como "perdonamiento" (Arragel, Éx 30,16 ), o de aborrer o aborrecer tenemos no solo "aborrición" sino también "aborrecimiento" (E3, Det 12,31) y "aborrimiento" (E5/E7, Det 7, 26).

Los resultados que encontramos en las Biblias se resumen en la siguiente tabla:

Tabla 5. Sufijos tradicionales -ura y -miento [Léxico único en cada Biblia]

\begin{tabular}{|l|c|c|c|}
\hline \multicolumn{1}{|c|}{ Biblias } & $\mathbf{- u r a}$ & $\mathbf{- m}(\boldsymbol{i})$ ento & TOTAL \\
\hline E3 & 230 & 149 & 379 \\
\hline E7/E5 & 91 & 245 & 336 \\
\hline Santillana & 61 & 209 & 270 \\
\hline Arragel & 54 & 104 & 158 \\
\hline
\end{tabular}

Como se observa en la Tabla 5, vuelve a repetirse la jerarquía de uso conservadora que veíamos en la Tabla 2. La suma de los sufijos tradicionales nos muestra que la Biblia de Arragel es la menos conservadora, mientras que en el polo opuesto encontramos de nuevo a la Biblia E3: 
+innovador $\rightarrow \rightarrow \rightarrow \rightarrow \rightarrow \rightarrow \rightarrow \rightarrow \rightarrow \rightarrow \rightarrow+$ tradicional

-ura/-miento: Arragel (158) < Santillana (270) < E7/E5 (336) < E3 (379)

En el caso de -ura no encontramos ninguna variación sobre este patrón: Arragel (54) < Santillana (61) < E7/E5 (91) < E3 (230). Mientras que en el caso de -miento la Biblia E3, la más tradicional, parece rechazarlo con fuerza en favor de los derivados en -ura, el otro sufijo tradicional con el que compite, y que como muestran los datos de CORDE es ciertamente el menos innovador de los dos (véase nota 20): Arragel (104) < E3 (149) < Santillana (209) < E7/E5 (245).

Por lo tanto, del análisis de los cuatro sufijos examinados podemos extraer la conclusión de que los sufijos innovadores -ción e-idad compiten en funcionalidad con los tradicionales -ura y -miento y tienden a sustituirlos. La Biblia de Arragel es también en este aspecto el romanceamiento más innovador, seguido de Lucena en la Biblia de Santillana. Del mismo modo E3 se muestra de nuevo como la traducción más conservadora y tradicional, quedando la Biblia E7/E5 en un término intermedio entre innovación y tradición. Las jerarquías propuestas para los morfemas derivativos coinciden exactamente con las observadas para -ísimo y -mente, y también con el análisis general de léxico innovador frente a tradicional que realizamos en el segundo apartado de este trabajo.

Lo que es destacable de los procesos de morfología derivativa que acabamos de examinar es que nos encontramos ante un ejemplo de combinación de un proceso tradicional común a todos (la técnica de creación nominal deverbal para expresar la misma relación existente en hebreo entre verbos y sustantivos que comparten la misma raíz) y su expresión en algunas de las versiones mediante sufijos innovadores en la lengua, frente al uso en otras versiones de sufijos bien establecidos en la tradición lingüística.

\section{EL PARTICIPIO DE PRESENTE:}

TRADICIÓN E INNOVACIÓN EN UNA ESTRUCTURA LÉXICO-SINTÁCTICA

Para finalizar este recorrido sobre la competencia de los usos innovadores y tradicionales en el ámbito de la creación léxica en las Biblias castellanas hemos examinado el uso verbal de los participios activos de presente construidos mediante la terminación -iente (<-ĚNTE(M)).

Nos interesa particularmente analizar el uso del participio de presente porque, en las Biblias traducidas del hebreo, esta estructura puede reflejar de nuevo dos fenómenos que en principio parecen resultar irreconciliables: una tendencia cultista y latinizante, por un lado, y una tenden- 
cia hebraizante de corte tradicional por el otro. Al igual que ocurría con -ISSIMUS, los participios de presente latinos en -ENS, -ENTIS no se transmitieron patrimonialmente (en su uso verbal) a las lenguas romances, sino que fueron recuperados posteriormente y muy particularmente en el siglo $\mathrm{XV}^{27}$. Resultan por lo tanto una innovación cultista y latinizante que está en plena efervescencia en la época en que se realizan las traducciones que estamos estudiando. Por el otro lado, una de la funciones del participio de presente castellano en las Biblias medievales es calcar con exactitud el valor temporal y aspectual del participio activo hebreo. Cierto es que este uso hebraizante solo ocurre de forma consistente en las traducciones sefardíes de después de la expulsión, normalmente mediante el uso de la variante apocopada del participio en -ién (teniente $>$ tenién) o -án (andante $>$ andán). Por lo general, en las Biblias romanceadas medievales su uso no es frecuente y se prefieren estructuras de relativo con verbo conjugado (por ejemplo en Éx 9, 20, el temién [Ferrara] frente a el que teme [E3], el que temió [Santillana] o el que ovo temor [Arragel]), aunque pueden encontrarse ejemplos de este uso hebraizante en todos los romanceamientos, como se muestra en el siguiente ejemplo, en el que el participio de presente, además de traducir un participio hebreo, tiene un claro uso verbal ya que rige un complemento directo empollas/ampollas:

Heb.: ve'al habehemá lišhín poréah aba'bu'ot bejol erês Miŝráyim (Éx 9, 9)

E19: $\quad$ Sobre las bestias por urcella creciente empollas en toda la tierra de Egibto

Santillana: E sobre las animalias fecho sarna produziente ampollas en toda tierra de Egipto

Arragel: $\quad$ E sobre las bestias una sarna floreciente ampollas en toda tierra de Egipto

En la Tabla 6, contabilizamos el número de versículos bíblicos en los que el texto hebreo subyacente presenta un participio activo y en los que las Biblias castellanas presentan igualmente un participio de presente, es decir, aquellos casos en los que el uso del participio parece ser un calco hebraizante. Además ofrecemos el porcentaje de casos en que este uso coincide con la tradición sefardí, representada por la Biblia de Ferrara y que nos da una idea del mecanismo extremo de traducción intracomunitario al

${ }^{27}$ Lapesa 1981, pp. 269-270; Pons Rodríguez en prensa. Véase además nuestra consulta en CORDE en la Tabla 6 del Apéndice I.

ANUARIO De Estudios Medievales, 45/1, enero-junio 2015, pp. 357-392

ISSN 0066-5061, doi:10.3989/aem.2015.45.1.12 
que se acercan o del que se alejan las versiones medievales en esta estructura $^{28}$ :

Tabla 6. Participios de presente en -iente en estructuras hebraizantes [Versículos con participio activo singular en la Biblia hebrea $\sim 5000$ versículos]

\begin{tabular}{|l|c|c|c|}
\hline \multicolumn{1}{|c|}{ Biblias } & -iente/-ién & $\begin{array}{c}\text { \% respecto al } \\
\text { hebreo } \mathbf{( 5 0 0 0} \\
\text { casos) }\end{array}$ & $\begin{array}{c}\text { \% respecto a } \\
\text { Ferrara }(\mathbf{8 0 0} \\
\text { casos en -ién) }\end{array}$ \\
\hline E3 & 25 & $0,50 \%$ & $3,12 \%$ \\
\hline E7/E5 & 29 & $0,58 \%$ & $3,62 \%$ \\
\hline Santillana & 195 & $3,90 \%$ & $24,37 \%$ \\
\hline Arragel & 41 & $0,82 \%$ & $5,12 \%$ \\
\hline Ferrara & 800 & $16 \%$ & --- \\
\hline
\end{tabular}

Como podemos observar la única Biblia que muestra un uso destacado del participio de presente en estructuras hebraizantes es la Biblia de Santillana, aunque supone solamente un $24 \%$ de las ocasiones en que la Biblia de Ferrara presenta dicho hebraísmo.

En la Tabla 7 presentamos el número total de uso de participios en -iente en aquellos casos en los que no existe un participio de presente hebreo subyacente y que, por lo tanto, no podemos considerar como hebraizantes sino más bien latinizantes:

Tabla 7. Participios de presente en -iente en estructuras no hebraizantes [Versículos en los que la Biblia hebrea no presenta un participio activo]

\begin{tabular}{|l|c|}
\hline \multicolumn{1}{|c|}{ Biblias } & -iente \\
\hline E3 & 16 \\
\hline E7/E5 & 25 \\
\hline Santillana & 55 \\
\hline Arragel & 33 \\
\hline
\end{tabular}

De la que podemos extraer la siguiente jerarquía de versiones de menos a más innovadoras:

$$
\begin{aligned}
& \text { +tradicional } \rightarrow \rightarrow \rightarrow \rightarrow \rightarrow \rightarrow \rightarrow \rightarrow \rightarrow \rightarrow \rightarrow \text { +innovador } \\
& \text { E3 (16) }>\text { E7E5 (25) }>\text { Arragel (33) }>\text { Santillana (55) }
\end{aligned}
$$

\footnotetext{
${ }^{28}$ Solo tenemos en cuenta los casos en -iente/-ién (es decir, los participios de la $2^{\mathrm{a}}$ y $3^{\mathrm{a}}$ conjugación) ya que son más fácilmente identificables para su tratamiento numérico. Ferrara presenta otros 1.300 casos de participio apocopado en -án que elevarían su porcentaje al $42 \%$, pero no los tenemos en cuenta para poder comparar sus resultados con los de las Biblias medievales.
} 
El doble uso del participio de presente que hemos observado nos sitúa ante una encrucijada linguístico-cultural que cada traductor resuelve de manera diferente. La Biblia E3, manteniendo su talante conservador, evita el uso del participio de presente activo latinizante en la creación léxica de autor; sin embargo, resulta sorprendente su rechazo absoluto a hebraizar el texto en estos casos, alejándose así de la tradición de las Biblias sefardíes tradicionales y adaptándose en gran medida al público no judío al que se destina la traducción. Arragel rechaza igualmente, como es habitual en él, los calcos hebraizantes, usando casi siempre estructuras verbales de relativo para traducir el participio de presente hebreo; en el resto de los casos lo incorpora a su vocabulario en la misma medida que E5/E7, es decir, de forma moderada. Lucena, sin embargo, aprovecha el participio de presente con frecuencia mucho mayor, tanto para crear estructuras latinizantes de autor, como para crear estructuras hebraizantes calcadas del hebreo. Parece indudable que la atracción de Martín de Lucena hacia el uso del participio de presente ( 250 casos en total) debe interpretarse como una búsqueda de estilo latinizante, ya que en los cuatro libros deuterocanónicos de la Biblia de Santillana, traducidos directamente del latín y en los que no hay posibilidad de transferencia del hebreo, Lucena utiliza dichos participios en más de 80 ocasiones y en el Nuevo Testamento (también parte de la Biblia de Santillana) lo hace en no menos de 400 pasajes. Seguramente podemos atribuir este comportamiento a dos factores: primero, a que es un traductor muy literal, tanto cuando traduce del hebreo como del latín; y segundo, porque tanto el participio hebraizante como el latinizante ofrecen el mismo resultado superficial en castellano, y su uso en ambos casos le permite cumplir una doble misión: calcar el tiempo verbal hebreo subyacente (siguiendo la tradición del método sefardí de traducción) y al mismo tiempo mostrarse como un traductor moderno, que se integra lingüísticamente en el ambiente cultista del Marqués de Santillana, para quien trabaja.

En los siguientes listados ofrecemos algunos ejemplos innovadores propios de cada traductor:

E3: bendiziente, cubriente, doziente, estendiente, faziente, remaniente, removiente, riente, saliente, veyente, veniente.

E7/E5: ardiente, combatiente, conveniente, espandiente, firviente, paciente, pareciente, perseguiente, rebolviente, reyente, requiriente, resplandeciente, retrayente, revertiente, tañiente, teniente.

Arragel: aburreciente, balbuciente, ciente, cognociente, creciente, diligiente, ferbiente, floreciente, impaciente, inconviniente, insabiente, inciente, nigligiente, obidiente, oliente, percuciente, quiriente, regidiente, residiente, revertiente, romaniente, rugiente, esciente, esplandeciente, vertiente. 
Santillana: abriente, adoleciente, añadiente, atrayente, aviente, beviente, bolviente, cayente, ciñiente, combatiente, comiente, condecendiente, consiguiente, conteniente, conveniente, cosiente, coziente, cubriente, descendiente, descubriente, destruyente, dirrumpiente, discurriente, doliente, dormiente, encendiente, entendiente, escriviente, escureciente, estendiente, fendiente, feneciente, firiente, fuyente, yaziente, lamiente, luziente, maniente, moviente, partiente, pereciente, perteneciente, plaziente, poniente, prendiente, produziente, prometiente, redarguiente, redimiente, regaleciente, regiente, requiriente, resistiente, respondiente, sabiente, sacudiente, sirviente, sosteniente, sostuviente, subiente, temiente, trayente, trascurriente, trasluziente.

\section{CARACTERIZACIÓN DE LOS ROMANCEAMIENTOS}

Una vez examinados los comportamientos innovadores o conservadores de las diferentes Biblias estudiadas, en las secciones que siguen quisiéramos extraer una serie de conclusiones particulares sobre los tres grupos observados.

\subsection{El estilo tradicional de E3}

Como hemos ido observando en los análisis precedentes, la Biblia E3 se presenta como la menos innovadora en los procesos de incorporación léxica y de morfología derivativa. Se ha destacado en numerosas ocasiones el carácter tradicional y judío de la traducción contenida en este códice ${ }^{29}$. Si bien es cierto que este romanceamiento medieval es el que mejor recoge la tradición bíblica oral de los judíos en castellano -tradición expresada más tarde por escrito en las traducciones sefardíes de después de la expulsión ${ }^{30}$ hay que destacar que su traductor no plasmó dicha práctica de traducción en toda su extensión y características, sino que realizó un esfuerzo considerable para adaptarla al público cristiano al que se dirigía. Dicho esfuerzo se refleja particularmente en la omisión consciente de algunos fenómenos de sintaxis hebraizante, característicos de los ladinamientos sefardíes, los cuales el traductor de E3 adapta a las estructuras correspondientes del castellano de uso general (por ejemplo, como hemos visto, al evitar usar el participio de

\footnotetext{
${ }^{29}$ Sachs 1948-1949; Lazar 1995, p. XIX.

${ }^{30}$ Amigo Espada 1983; Hauptmann, Littlefield 1987, pp. 15-50, Lazar 1994, pp. XLI; 1995; 2000, pp. XVI-XXX; Pueyo Mena 2008, 2011, 2012.
} 
presente activo hebraizante y sustituirlo por estructuras de relativo con verbo conjugado).

En lo que respecta al léxico el texto de E3 se ciñe al vocabulario tradicional común, mostrando además coherencia interna en el uso de dicho léxico, evitando la incorporación de sinónimos no propiciados por el texto hebreo subyacente. Igualmente se atiene a la tradición de mantener casi siempre el orden de palabras del hebreo (licencia lingüística favorecida por el orden de palabras variable de la sintaxis castellana).

En conclusión, el traductor de E3 se muestra sensible al público cristiano para el que traduce, el cual desconoce el texto hebreo subyacente, por lo que trata de evitar construcciones que requieran su conocimiento para poder ser interpretadas. Al mismo tiempo, no se observa la incorporación de léxico innovador típico del siglo XV. Este hecho puede deberse a la datación temprana de la traducción -un extremo que debe estudiarse con mayor detenimientoo bien resultar de un intento de mantenerse fiel a la tradición judía y al mismo tiempo acercarse al público cristiano del siglo XV: el traductor adapta en lo posible la sintaxis hebrea al castellano medieval, pero muestra apego a su tradición en aquellos aspectos del texto en los que no existe una incompatibilidad lingüística que así se lo impida (léxico, exégesis, orden de palabras, etc.).

\subsection{EI estilo variable de E7/E5}

Como ya hemos señalado en un estudio anterior ${ }^{31}$ el romanceamiento transmitido en los códices E7 y E5 se caracteriza por un estilo de traducción interpretativa en la que se despliega una variación léxica bastante más diversificada que la de las demás versiones ${ }^{32}$. Este proceder contrasta de manera radical con el que hemos visto en el caso de E3, pues en E7/E5 el romanceador casi nunca se adhiere decididamente a un vocablo determinado para traducir una palabra hebrea sino que emplea diferentes sinónimos. Por ejemplo, a la hora de traducir maté / šébet E3 siempre emplea vara mientras que en E7/E5 encontramos blago, piértego, verdugo, palo, lança, mando, saeta, tenimiento, venablo, verga y yugo ( $c f$. la Tabla 3$)^{33}$. Esa búsqueda intencionada de varie-

\footnotetext{
${ }^{31}$ Pueyo Mena, Enrique-Arias 2013.

${ }^{32}$ Littlefield 1996, p. VII, ya había observado el carácter marcadamente interpretativo del romanceamiento E7 al que caracteriza en los siguientes términos: "a radical departure from the translation tradition found in the other extant manuscripts. [...] the E7 text is often paraphrastic and interpretative, expanding upon the M[asoretic] T[ext]".

${ }^{33}$ En el detallado trabajo cuantitativo de M. Menéndez Aneiros sobre el léxico de los romanceamientos medievales del Cantar de los cantares se pone de manifiesto que E5 es la versión que más se aparta de emplear un mismo vocablo romance para cada lema del original
} 
dad léxica en principio parecería ser un terreno fértil para la incorporación de cultismos y sin embargo no es así. El traductor recurre a la variación léxica bien como recurso estilístico o como manera de matizar su traducción y ayudar a la comprensión del texto, pero ese distanciamiento del fondo común tradicional se hace mediante el empleo de voces patrimoniales. Ello es así incluso en aquellos casos en los que E7/E5 emplea vocablos que no aparecen en ninguno de los otros romanceamientos: corriente para traducir nahal "río", ribera para safá en su acepción de "orilla", novillo para par "toro", cabdillo para nasi "mayoral", o el empleo de un hebraísmo crudo, çafón, para el punto cardinal expresado por este lema hebreo.

Por lo que respecta a la morfología, hemos visto que E7/E5 desconoce el sufijo -ísimo, y emplea formaciones en -mente, -ción, -idad en mayor medida que la más tradicional E3 pero muy por debajo de las traducciones más innovadoras de las Biblias de Santillana y Arragel.

Cabe preguntarse por otro lado si la adopción relativamente escasa de neologismos cultos se debe a una fecha temprana de composición del romanceamiento; en tal caso el traductor no los emplearía sencillamente porque no tiene esa opción. Pero no parece ser el caso; por ejemplo, E7/E5 emplea de manera singular la expresión exceptiva salvante "excepto", expresión que continúa en portugués actual y que tuvo cierta fortuna en la historia del español (CORDE la documenta 21 veces en 17 textos de diferentes géneros) pero que no se documenta antes de 1400. La localización y análisis de otras formas que permitan datar el término post quem del romanceamiento confirmaría que estamos ante un texto compuesto durante el siglo $\mathrm{XV}$ y por tanto la escasa incorporación de neologismos cultos es en efecto una opción consciente del autor $^{34}$.

\subsection{El "sabio" converso Lucena}

De Martín de Lucena se sabe poco documentalmente: era judío converso -como lo indica su apodo "el Macabeo" y la posterior persecución que sufriera su familia por parte de la Inquisición- y ejerció de médico personal del Marqués de Santillana ${ }^{35}$, para quien además tradujo los Evangelios y las

hebreo al exhibir el mayor grado de riqueza léxica de todas las traducciones (Menéndez Aneiros 2010, p. 33).

${ }^{34}$ El editor del manuscrito ( $c f$. Littlefield 1996, pp. X-XVII) considera que E7 refleja la lengua del primer cuarto del siglo XV. ción.

${ }^{35} \mathrm{Su}$ condición de doctor en medicina aparece explicita en los incipit de sus obras de traduc- 
epístolas paulinas ${ }^{36}$ y el comentario latino de Benvenuto de Imola al Purgatorio de Dante. Por nuestra parte añadimos a la nómina de su obra la traducción completa del Antiguo Testamento (del hebreo y del latín), trabajo complementario al del Nuevo Testamento realizado para el Marqués de Santillana ${ }^{37}$.

Lucena se nos presenta como un traductor culto, tanto para la comunidad judía como para la cristiana, y muy literal. Ambas características emanan de su condición de converso de primera generación: traduce a la judía pero usa un molde léxico cuatrocentista que le sirve muy bien al doble propósito de mantener la tradición heredada y de actualizar el lenguaje de los "antiguos hebreos" del que nos habla la conocida introducción de la Biblia de Ferrara.

En lo lingüístico ya hemos visto que el uso del participio de presente le sirve para mantener un estado ambiguo entre tradición hebraizante e innovación latinizante. En general, su uso del léxico, como hemos visto, mantiene el equilibrio entre la traducción literal tradicional y la incorporación de cultismos o voces patrimoniales más modernas que las usadas por otras Biblias más tradicionales.

En definitiva, Martín de Lucena resuelve la tensión lingüística de la que venimos hablando y su propia tensión cultural como judío converso de manera sencilla: traduce literalmente del hebreo y del latín -incluso preservando hebraísmos sintácticos extremos, como marca la tradición judía sefardí (y también la traducción ad verbum del latín al castellano característica de la época)- pero incorpora a este molde tradicional, y a la base léxica común heredada del mismo, no solamente numerosos cultismos y latinismos sino también vocablos vernáculos que no son propios de las traducciones bíblicas tradicionales contemporáneas.

\subsection{El "sabio" rabino Arragel}

La Biblia que compuso Mosé Arragel para el maestre de la Orden de Calatrava Don Luis de Guzmán es un caso ciertamente excepcional al ser la única biblia medieval romanceada en que tenemos noticia cierta de su patrocinador y autor e incluso un amplio y esclarecedor prólogo en que el autor explica con detalle los criterios de traducción empleados. En particular el rabino aborda de manera explícita el problema al que se enfrentan los traductores bí-

\footnotetext{
36 “Aquí comiençan los Santos Evangelios en romance, los cuales son romanciados por el revendo dotor maestre Martín de Lucena el Macabeo, por mandado del excelentíssimo cavallero Yñigo López de Mendoça (Incipit a Evangelios y Epístolas Paulinas”, ms. BNE 9556, f. 1ra).

${ }^{37}$ Véase Pueyo Mena, Enrique Arias 2013, pp. 210-215.
} 
blicos cuatrocentistas de, por un lado, preservar la esencia del original hebreo y al mismo tiempo producir un texto entendible por un público cristiano que no conoce las peculiaridades de la lengua fuente. Arragel expone cómo en su traducción se propuso hacer concordar el hebreo con la Vulgata en la medida de lo posible, y solo en aquellas ocasiones en que las dos versiones fueran irreconciliables podría inclinarse por la versión hebrea:

la vía por mí tomada en esta trasladación (...) si es en lo más possible, concordar la jerónima trasladación con el ebraico, como la sentencia sea una, a las vezes partes anteponiendo, a las vezes posponiendo, como la glosa sea muy conforme. E do concordar non los pudiere, seguiré sobre el ebraico, siguiendo en el jerónimo mandado (f. 13v).

Pero además Arragel muestra una clarividencia extraordinaria para la época al abordar la cuestión de las diferencias lingüísticas entre judíos y cristianos cultos (acostumbrados al castellano latinizante de la época o al latín). El rabino entiende que el arte moderno de la traducción bíblica exige la incorporación de términos latinos, pues el latín ya es parte del castellano; aun así, para evitar malentendidos, incluirá junto al latín la oportuna aclaración en romance pues no todos los potenciales lectores, y en particular los judíos, tienen el mismo nivel de acceso a los latinismos:

Mi intención en esta obra fue beyendo oy la cristiana nación muy sabia e muy puros en la su castellana lengua; pero oy más que en los antiguos tiempos, como á avido multitud de sabios, la común gente platicando con los sabios an aprendido de la su ciencia, e aún de la su latina lengua, a tanto es ya la ciencia e lengua latina espandida en Castilla, que los cavalleros e escuderos e cibdadanos an dexado el puro castellano, e con ello an mixto mucho latín, a tanto que el latín es convertido en castellano. Digo: tanto que comúnmente an muchas palabras latinas la gente en logar de castellano; e esto así a mí causó en el texto e glosa d'esta obra dexar muchas partes latinas por romançar, por en possessión de manifiestas las yo tener; pero por cuanto esta dicha manifestación non vernía a todos, e por sola una parte se pierde una leición, e por una leición un libro, mayormente a los judíos, por tanto acordé de les tornar romançar aquellas mismas partes o palabras que en esta obra quedaren en latín o en ebraico, por que el judío non se espante del latín e lo bien entienda, nin menos el cristiano de las ebraicas palabras, e entendidas las partes, cada una d'estas naciones non saltará a non tomar lo que oyere e pelear por se non entender (f. 15r-v).

En la traducción de Arragel son numerosos los ejemplos de latinismos crudos que siguen directamente la Vulgata, a los que añade la explicación pertinente siguiendo el texto hebreo: 
Gé 4, 2

Heb.: $\quad$ ve-Cayin hayá 'obed adamá

Vulg.: $\quad$ et Cain agricola

Arragel: $\quad$ E Caín agricola (conviene saber, ciente en las labores de la tierra)

Santillana: E Caím fue labrador de tierra

E3: $\quad$ E Caín era labrador de tierra

Sam1 21, 15

Heb.: $\quad$ iš mištaguea

Vulg.: $\quad$ hominem insanum (21:14)

Arragel: $\quad$ algún omne insanum (conviene saber, loco)

Santillana: este omne es loco

E7/E5: $\quad$ es menguado este omne

E3: $\quad$ omne que se enloquece

$\operatorname{Re} 223,5$

Heb.: ve-hišbit et ha-kemarim

Vulg.: $\quad$ et delevit aruspices

Arragel: $\quad$ E mandó vedar los auruspites (conviene saber, los prestes de los ídolos)

Santillana: E quitó los clérigos

E7/E5: $\quad$ E fizo desbaratar a los clérigos

E3: $\quad$ E tiró los frailes

$\operatorname{Cr} 1$ 15, 20

Heb.: binbalim 'al 'alamot

Vulg.: in nablis arcana cantabant

Arragel: $\quad$ con nables (conviene saber, con instrumentos de músicos) de muchas maneras

Santillana: con laudes por cantos ocultos

E7/E5: $\quad$ con órganos sobre alto siempre

E3: $\quad$ con gaitas con estrumentes

De forma inversa, otras veces Arragel presenta la lectura tradicional o vernácula (como muestran las otras versiones) como opción principal dentro del texto y ofrece sobre la línea y en tinta roja una lectura alternativa siguiendo 
la Vulgata. Algunas veces estas lecturas alternativas son copia directa de la Vulgata en latín, pero en otras ocasiones se adaptan al castellano. He aquí una pequeña muestra de algunos casos encontrados en Génesis:

Gé 23, 9

Heb.: $\quad$ yitenena li betojejem la-ahuzat cáber

Vulg.: $\quad$ tradat mihi eam coram vobis in possessionem sepulchri

Arragel: $\quad$ tal que me sea heredat [possesión] para sepulcro

Santillana: me le dé entre vosotros por heredat de sepultura

E3: $\quad$ me la dé entre vosotros por heredad de fonsario

Gé 29, 2

Heb.: $\quad$ vehiné šam šelošá 'edré ŝon robŝim 'aleha

Vulg.: $\quad$ tresque greges ovium accubantes iuxta eum

Arragel: $\quad$ E estavan cerca d'él tres rabaños [greges] de ovejas

Santillana: E ende estavan tres hatos de ganado arrodillados sobre él

E7/E5: $\quad$ E avié allí tres greyes de ovejas paciendo sobre ella

E3: $\quad$ E avía ý tres manadas de ovejas que yazían cerca d'él

Gé 38, 15

Heb.: $\quad$ vayireha Yehudá vayaȟsebeha le-zoná

Vulg.: $\quad$ quam cum vidisset Iudas suspicatus est esse meretricem

Arragel: E como la vio Juda contóla por mundaria [meretriz]

Santillana: E vióla Juda e pensóla ser mundaria

E7/E5: $\quad$ E vídola Judá e tóvola por mundaria

E3: $\quad$ E vídola Judá e pensó que era mala muger

Diferentes estudios ${ }^{38}$ han observado cómo la versión de Arragel combina un fondo tradicional hebraizante con intervenciones para cumplir el encargo de Luis de Guzmán de conciliar el texto con la Vulgata y dotarle además del estilo moderno latinizante propio de la época. En consecuencia la Biblia de Arragel se distingue por evitar los hebraísmos léxicos y sintácticos más violentos en el uso normal castellano e intensificar la introducción de latinismos y lecturas de la Vulgata. No obstante, las intervenciones del traductor no eliminan completamente la impronta hebraizante por lo que el texto resultante es un híbrido donde tenemos elementos que son moneda común en las

\footnotetext{
${ }^{38}$ Enrique-Arias 2004, 2006, entre otros.
} 
traducciones más cercanas al hebreo (si para traducir ha interrogativo, calco del infinitivo absoluto hebreo, pluralia tantum) junto a rasgos atribuibles a un afán de acercarse a la prosa humanística en boga en el momento: ortografía latinizante, calcos sintácticos y orden de palabras influidos por el latín, y en general tendencia a la prolijidad y ampulosidad.

El análisis léxico cuantitativo que hemos llevado a cabo en las páginas precedentes confirma el afán renovador de la Biblia de Arragel en lo que respecta a la selección de vocabulario pues es, con diferencia, el romanceamiento que emplea opciones más innovadoras para cada uno de los parámetros de variación léxica que hemos analizado.

\section{CONCLUSIÓN}

Por su considerable número y extensión y por la riqueza de los datos lingüísticos que contienen las Biblias castellanas medievales son un terreno rico y fértil en materiales para el estudio de la historia del léxico. Los romanceamientos de principios del XV que hemos analizado en estas páginas representan un capítulo excepcional en la cultura europea medieval ya que son el resultado del trabajo de traductores judíos al servicio de señores cristianos que deseaban incorporar a sus bibliotecas privadas Biblias castellanas traducidas directamente del hebreo. El estudio contrastivo de las diferentes soluciones de los traductores ante el Texto Masorético nos permite asomarnos a las encrucijadas sociales y culturales que se dan en la Castilla de principios del XV: los encuentros y desencuentros entre la cultura judía y la cristiana en un clima cultural en el que conviven la tradición medieval y los anticipos de la modernidad prehumanista. Todos estos elementos tienen ramificaciones lingüísticas que podemos observar en el léxico empleado en las traducciones de la Biblia, en cómo cada traductor conjuga de manera particular el sistema de traducción tradicional desarrollado por los judíos españoles en la Edad Media con la traducción erudita que anticipa el biblismo renacentista de corte humanista abocado a la recuperación de la veritas hebraica.

El análisis que hemos ofrecido en estas páginas solo ha sido posible gracias a la disponibilidad del corpus integral de los romanceamientos medievales disponibles en la web del proyecto Biblia Medieval. Estas herramientas permiten por primera vez hacer estudios contrastivos a gran escala que nos acercan a una caracterización lingüística completa de los diferentes textos y por ende nos permiten entender con una base empírica sólida el carácter de cada traducción. Confiamos, en definitiva, en que estos nuevos recursos nos permitan ofrecer una base renovada para el estudio y justipreciación de este valioso corpus textual. 


\section{BIBLIOGRAFÍA CITADA}

Amigo Espada, Lorenzo (1983), El Pentateuco de Constantinopla y la Biblia medieval romanceada: criterios y fuentes de traducción, Salamanca, Universidad Pontificia.

Barco, Javier del (2011), Estudio lingüístico de glosas romances en un manuscrito exegético hebreo del s. XIII, "Romance Philology" 65/2, pp. 173-193.

Bunis, David M. (1996), Translating from the Head and from the Heart: The Essentially Oral Nature of the Ladino Bible-Translation Tradition, en Busse, Winfried; Varol Bornes, Marie-Christine (eds.), Hommage à Haïm Vidal Sephiha, Berna, Peter Lang, pp. 337-357.

Company Company, Concepción (2012), Condicionamientos textuales en la evolución de los adverbios en -mente, "Revista de Filología Española" 92/1, pp. 9-42.

Corpus diacrónico del español (CORDE), Real Academia Española, http://www.rae.es [consulta: 19/07/2014].

Enrique-Arias, Andrés (2004), Texto subyacente hebreo e influencia latinizante en la traducción de la Biblia de Alba de Moisés Arragel, en Alsina, Victòria; Brumme, Jenny; Garriga, Cecilio; Sinner, Carsten (eds.), Traducción y estandarización. La incidencia de la traducción en la historia de los lenguajes especializados, Madrid, Iberoamericana Fráncfort, Vervuert, pp. 99-111.

Enrique-Arias, Andrés (2006), Sobre el parentesco entre la Biblia de Alba y la Biblia de la Real Academia de la Historia ms. 87, "Romance Philology" 59, pp. 21-43.

Enrique-Arias, Andrés (dir.) (2008), Biblia Medieval. Universitat de les Illes Balears, http://www.bibliamedieval.es [consulta: 07/08/2014].

Fellous-Rozenblat, Sonia (1992), The Biblia de Alba, its Patron, Author and Ideas, en La Biblia de Alba in the Collection of the Palacio de Liria, Madrid. An illustrated Manuscript Bible in Castilian. Companion volume, Madrid, Fundación Amigos de Sefarad - Londres, Facsimile Editions, pp. 49-64.

Gago Jover, Francisco; Enrique-Arias, Andrés; Pueyo Mena, F. Javier, Concordancias de textos bíblicos españoles, http://www.hispanicseminary.org/t\&c/test/index-es.htm [consulta: 07/08/2014].

Jörnving, Rolf (1962), El elativo en -isimo en la lengua castellana de los siglos XV y XVI, "Studia Neophilologica" 24, pp. 57-83.

Hauptmann, Oliver H. (†); Littlefield, Mark G. (1987), Escorial Bible i.j.4. vol. 2, Madison, The Hispanic Seminary of Medieval Studies.

Lapesa, Rafael (1981), Historia de la lengua española, Madrid, Gredos. 
Lazar, Moshe (1994), Ladinando la Biblia entre los sefardies mediterráneos: Italia, Imperio Otomano y Viena, en Hassan, Jacob M.; Berenguer Amador, Ángel (eds.), Introducción a la Biblia de Ferrara. Actas del Simposio Internacional sobre la Biblia de Ferrara (Sevilla, 25-28 de noviembre de 1991), Madrid, Sefarad 92 - Comisión Nacional Quinto Centenario, pp. 347-442.

Lazar, Moshe (1995), Biblia Ladinada I.J.3, 2 vols., Madison, Hispanic Seminary of Medieval Studies.

Lazar, Moshe (1995), Siddur Tefillot. A Woman's Ladino Prayer Book [Paris BN Esp. 668. 15th c.], Culver City, Labyrinthos.

Lazar, Moshe (2000), The Ladino Scriptures. [Constantinople-Salonica 1540-1568], Lancaster, Labyrinthos.

Littlefield, Mark (1992), Escorial Bible I.ii.19. Edition, study and notes, Madison, Hispanic Seminary of Medieval Studies.

Littlefield, Mark (1996), Escorial Bible I.I.7. Edition, study, notes and glossary, Madison, Hispanic Seminary of Medieval Studies.

Llamas, José (1950-1955), Biblia medieval romanceada judío-cristiana. Versión del Antiguo Testamento en el siglo XIV, sobre los textos hebreo y latino, 2 vols., Madrid, Consejo Superior de Investigaciones Científicas.

Menéndez Aneiros, Mónica (2010), Variación léxica en las versiones medievales romanceadas del "Cantar de los Cantares", Palma de Mallorca, Universidad de las Islas Baleares (tesis de licenciatura).

Pons Rodríguez, Lola (2012), La doble graduación muy -ísimo en la historia del español y su cambio variacional, en Pato, Enrique; Rodríguez Molina, Javier (eds.), Estudios de filología y lingüística españolas. Nuevas voces en la disciplina, Berna, Peter Lang, pp. 93-133.

Pons Rodríguez, Lola (en prensa), La lengua del Cuatrocientos más allá de las Trescientas, en García Martín, José María (ed.), Actas del IX Congreso Internacional de Historia de la Lengua Española (Cádiz, septiembre de 2012) Madrid, Iberoamericana - Fráncfort, Vervuert.

Pueyo Mena, F. Javier (2008), Biblias romanceadas y en ladino, en Hassán, Iacob M.; Izquierdo Benito, Ricardo (coords.); Romero, Elena (eds.), Sefardies: Literatura y lengua de una nación dispersa, Cuenca, Universidad de Castilla-La Mancha, pp. 193-263.

Pueyo Mena, F. Javier (2011), Séfer Hésec Šelomó: edición de Génesis / Berešit (cps. 1-10) en Romero Castelló, Elena (ed.), Estudios sefardies dedicados a la memoria de Iacob M. Hassán (z"l), Madrid, Consejo Superior de Investigaciones Científicas, pp. 433-478.

Pueyo Mena, F. Javier (2012), “Tu pueblo mi pueblo y tu Dio mi Dio”: el libro de Rut en la Biblia de Abraham Asá, "eHumanista" 20, pp. 263-295. 
Pueyo Mena, F. Javier; Enrique-Arias, Andrés (2013), Los romanceamientos castellanos de la Biblia hebrea compuestos en la Edad Media: manuscritos y traducciones, "Sefarad" 73/1, pp. 165-224.

Sachs, George E. (1948-1949), Fragmento de un estudio sobre la Biblia medieval romanceada, "Romance Philology" 2, pp. 217-228.

Serradilla Castaño, Ana (2005), Evolución de la expresión del grado superlativo absoluto en el adjetivo: las perífrasis sustitutivas del superlativo sintético en español antiguo, "CAUCE. Revista Internacional de Filología y su Didáctica” 28, pp. 357-38.

Szpiech, Ryan (en prensa), Translating Between the Lines: Medieval Polemic and Romance Bibles.

Zieliński, Andrzej (2013), Evolución semántico-sintáctica del sufijo superlativo -ísimo en castellano, "Romanica Cracoviensia" 13, pp. 105-114.

APÉNDICE

Tabla 1. Búsqueda de *ción, *cion, *çion, *çión (CORDE)

\begin{tabular}{|l|l|l|l|l|} 
Siglo & Casos & Total palabras & $\%$ & Casos por palabra \\
\hline XIII & 9.703 & 8.958 .728 & $0.10 \%$ & 1 por cada 923 palabras \\
XIV & 21.423 & 9.734 .293 & $0.22 \%$ & 1 por cada 453 palabras \\
XV & 94.219 & 23.786 .437 & $0.39 \%$ & 1 por cada 252 palabras \\
\hline
\end{tabular}

Tabla 2. Búsqueda de *idad, *idat (CORDE)

\begin{tabular}{|l|r|r|r|l|}
\hline \multicolumn{1}{|c|}{ Siglo } & \multicolumn{1}{c|}{ Casos } & \multicolumn{1}{c|}{ Total palabras } & \multicolumn{1}{c|}{ \% } & \multicolumn{1}{c|}{ Casos por palabra } \\
\hline XIII & 5.260 & 8.958 .728 & $0.05 \%$ & 1 por cada 1703 palabras \\
XIV & 7.604 & 9.734 .293 & $0.07 \%$ & 1 por cada 1280 palabras \\
XV & 35.439 & 23.786 .437 & $0.15 \%$ & 1 por cada 671 palabras \\
\hline
\end{tabular}

Tabla 3. Búsqueda de *ura (CORDE)

\begin{tabular}{|l|c|r|r|c|}
\hline \multicolumn{1}{|c|}{ Siglo } & Casos & \multicolumn{1}{c|}{ Total palabras } & \multicolumn{1}{c|}{ \% } & Casos por palabra \\
\hline XIII & 27.310 & 8.958 .728 & $0.30 \%$ & 1 por cada 328 palabras \\
XIV & 18.490 & 9.734 .293 & $0.18 \%$ & 1 por cada 526 palabras \\
XV & 55.212 & 23.786 .437 & $0.20 \%$ & 1 por cada 430 palabras \\
\hline
\end{tabular}

Tabla 4. Búsqueda de *mento, *miento (CORDE)

\begin{tabular}{|l|r|r|r|r|}
\hline \multicolumn{1}{|c|}{ Siglo } & \multicolumn{1}{c|}{ Casos } & \multicolumn{1}{c|}{ Total palabras } & \multicolumn{1}{c|}{ \% } & Casos por palabra \\
\hline XIII & 27.310 & 8.958 .728 & $0.20 \%$ & 1 por cada 409 palabras \\
XIV & 18.490 & 9.734 .293 & $0.19 \%$ & 1 por cada 533 palabras \\
XV & 55.212 & 23.786 .437 & $0.28 \%$ & 1 por cada 347 palabras \\
\hline
\end{tabular}


Tabla 5. Implantación de algunas voces patrimoniales (CORDE)*

\begin{tabular}{|c|c|c|}
\hline Vocablo y búsqueda CORDE & Ocurrencias ss. XIII-XIV & Ocurrencias s. XV \\
\hline príncipe $/ p r \star n * i p e *$ & (1804) 1 por cada 10.362 & (7363) 1 por cada 3.231 \\
\hline capitán / capit*n* & (1286) 1 por cada 14.536 & (4772) 1 por cada 4.985 \\
\hline condestable / co*desta* & (5) 1 por cada 3.738 .604 & (1957) 1 por cada 12.155 \\
\hline gente / gente & (6726) 1 por cada 2.779 & (22516) 1 por cada 1.056 \\
\hline pueblo / pueblo & (7478) 1 por cada 2.500 & (13018) 1 por cada 1.827 \\
\hline compaña / co*paña/co*panna & (2115) 1 por cada 8.838 & (1956) 1 por cada 12.161 \\
\hline concejo / concejo/conceio & (3203) 1 por cada 5.836 & (1927) 1 por cada 12.344 \\
\hline derecha izquierda / derecha *quierda & (2062) 1 por cada 9.065 & (3423) 1 por cada 6.949 \\
\hline diestra siniestra / diestra siniestra & (933) 1 por cada 20.035 & (1233) 1 por cada 19.292 \\
\hline fabla / fabla* & (3334) 1 por cada 5607 & (3498) 1 por cada 6.800 \\
\hline lengua / 1 *ngua* & (1846) 1 por cada 10126 & (3977) 1 por cada 5.981 \\
\hline remanecer / remane* & (390) 1 por cada 47.931 & (127) 1 por cada 187.295 \\
\hline vestimenta / *estimenta & (45) 1 por cada 415.400 & (98) 1 por cada 242.719 \\
\hline corriente / corriente & (45) 1 por cada 415.400 & (280) 1 por cada 84.952 \\
\hline novillo / no*illo* & (7) 1 por cada 2.670 .432 & (36) 1 por cada 660.734 \\
\hline
\end{tabular}

* Distribución total del número de palabras en CORDE por período: XIII-XIV (18.693.021) / XV (23.786.437). Las casillas sombreadas en la tercera columna indican que la forma ha aumentado su uso claramente en el siglo XV, el sombreado en la segunda columna indica formas más comunes en los siglos XIII-XIV.

Tabla 6. Búsqueda de *iente* (CORDE)*

\begin{tabular}{|l|r|r|l|}
\hline \multicolumn{1}{|c|}{ Siglo } & \multicolumn{1}{c|}{ Casos } & Total palabras & \multicolumn{1}{c|}{ Casos por palabra } \\
\hline XIV** & 7.543 & 9.734 .293 & 1 por cada 1.290 palabras \\
XV & 39.279 & 23.786 .437 & 1 por cada 605 palabras \\
\hline
\end{tabular}

* No discriminamos otras formas plenamente nominales, verbales o adjetivales que puedan coincidir en la terminación (como tú sientes < sentir, diente, poniente, valiente, etc.), ya que CORDE no está etiquetado, sin embargo no son muchos los ejemplos de estos sustantivos, verbos y adjetivos plenos en -iente en español que además presenten variaciones significativas de uso entre el XIV y el XV. Como observamos el uso general de formas en -iente se duplica en el siglo XV por lo que es muy posible que muchos de los casos se deban al uso innovador del participio de presente.

**Excluimos el siglo XIII para no distorsionar los resultados con la presencia de formas apocopadas en -ient, muy frecuente en la época.

Fecha de recepción del artículo: agosto 2014

Fecha de aceptación y versión final: febrero 2015 